\title{
Collateral effects of beekeeping: impacts on pollen-nectar resources and
}

\section{wild bee communities}

\author{
Anna Torné-Noguera ${ }^{a, k}$, Anselm Rodrigo ${ }^{a, b}$, Sergio Osorio ${ }^{a}$, Jordi Boscha

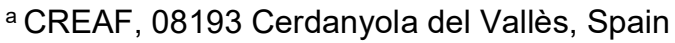 \\ b Universitat Autònoma de Barcelona, 08193 Cerdanyola del Vallès, Spain
}

This is the author's version of a work that was accepted for publication in Basic and applied ecology (Ed. Elsevier). Changes resulting from the publishing process, such as peer review, editing, corrections, structural formatting, and other quality control mechanisms may not be reflected in this document. Changes may have been made to this work since it was submitted for publication. A definitive version was subsequently published in Torné-Noguera, A., et al. "Collateral effects of beekeeping: impacts on pollen-nectar resources and wild bee communities" in Basic and applied ecology, vol. 17, issue 3 (May 2016), p. 199-209. DOI 10.1016/j.baae.2015.11.004

*Corresponding author. Tel.: +34 93 5814851; fax: +34 935814151.

E-mail address: a.torne@creaf.uab.cat. 


\section{Abstract}

2 Due to the contribution of honey bees (Apis mellifera) to wild flower and crop pollination,

3 beekeeping has traditionally been considered a sustainable practice. However, high honey bee

4 densities may have an impact on local pollen and nectar availability, which in turn may

5 negatively affect other pollinators. This is exacerbated by the ability of honey bees to recruit

6 foragers to highly rewarding flower patches. We measured floral resource consumption in

7 rosemary (Rosmarinus officinalis) and thyme (Thymus vulgaris) in 21 plots located at different

8 distances from apiaries in the scrubland of Garraf Natural Park (Barcelona), and related these

9 measures to visitation rates of honey bees, bumblebees (Bombus terrestris) and other

10 pollinators. In the same plots, we measured flower density, and used pan traps to characterize

11 the wild bee community. Flower resource consumption was largely explained by honey bee

12 visitation and marginally by bumblebee visitation. After accounting for flower density, plots close

to apiaries had lower wild bee biomass. This was due to a lower abundance of large bee species, those more likely to be affected by honey bee competition. We conclude that honey bees are the main contributors to pollen/nectar consumption of the two main flowering plants in the scrubland, and that at the densities currently occurring in the park $\left(3.5\right.$ hives $\left./ \mathrm{km}^{2}\right)$ the wild bee community is being affected. Our study supports the hypothesis that high honey bee densities may have an impact on other pollinators via competition for flower resources.

\section{Zusammenfassung}

Wegen des Beitrages der Honigbiene (Apis mellifera) bei der Bestäubung von Wildblumen und

Nutzpflanzen wurde die Bienenhaltung traditionell als eine nachhaltige Aktivität angesehen. Indessen können hohe Honigbienendichten Auswirkungen auf die lokale Verfügbarkeit von Nektar und Pollen haben, was wiederum andere Bestäuber negativ beeinflussen könnte. Dies wird verstärkt durch die Fähigkeit der Honigbiene, Sammlerinnen zu lohnenden Sammelstellen zu dirigieren. Im Buschland des Garraf-Naturparks bei Barcelona maßen wir den Verbrauch von Blütenressourcen an Rosmarin (Rosmarinus officinalis) und Thymian (Thymus vulgaris) an 21 Standorten, die unterschiedlich weit von Bienenständen entfernt lagen, und setzten diese Werte in Bezug zu den Besuchsraten von Honigbienen, Hummeln (Bombus terrestris) und sonstigen 
31 Farbschalen ein, um die Wildbienengemeinschaft zu erfassen. Die Nutzung der Blüt enressou

32 wurde weitgehend durch die Besuchsraten der Honigbiene erklärt und in geringfügigem Maße

33 durch Hummelbesuch. Nach Berücksichtigung der Blütendichte wiesen Standorte in der Nähe

34 von Bienenständen eine geringere Wildbienen-Biomasse auf. Dies war auf eine geringere

35 Abundanz der großen Wildbienenarten zurückzuführen, also der Arten, die wahrscheinlich

36 durch die Konkurrenz der Honigbiene beeinträchtigt werden. Wir schließen, dass Honigbienen

37 den größten Beitrag zum Pollen- bzw. Nektarverbrauch bei den beiden wichtigsten

38 Blütenpflanzen des Gebietes leisten und dass die Wildbienengemeinschaft bei den

39 gegenwärtigen Honigbienendichten im Park (3.5 Völker/km²) beeinflusst wird. Unsere

40 Untersuchung unterstützt die Hypothese, dass hohe Honigbienendichten durch Konkurrenz um

41 Blütenressourcen einen Einfluss auf andere Bestäuber haben könnten.

42

43 Keywords: Bee conservation; Exploitative competition; Honey bees; Pollinator community;

44 Resource consumption.

45

46 


\section{Introduction}

The introduction of large populations of highly competitive species into a new area may affect resident populations, ultimately resulting in changes in the structure of native communities (Ehrenfeld, 2010; Levine et al., 2003). This may occur when exotic species, introduced either accidentally or intentionally, turn invasive and compete for limited resources with local species occupying a similar niche (Byers, 2000; Petren \& Case, 1996). In addition to exotic species, domesticated species may also affect resident species. A clear example is the presence of cattle or sheep in natural or semi-natural areas, potentially competing with large herbivores for pasture (Stewart, Bowyer, Kie, Cimon, \& Johnson, 2002; Young, Palmer, \& Gadd, 2005). Domesticated animals benefit from human assistance, including protection against predators and veterinary care, and therefore may have a competitive advantage over wild species.

Among domesticated animals, the European honey bee (Apis mellifera) is undoubtedly one of the globally most spread. Native to Eurasia and Africa, honey bees are now kept in all continents except Antarctica, initially for honey production (Crane, 1990), but mostly for crop pollination (Free, 1993), being, by far, the main managed pollinator worldwide (Aizen \& Harder, 2009; Breeze et al., 2014; Garibaldi et al., 2013). Consequently, beekeeping has traditionally been considered a beneficial practice, and its sustainability has been taken for granted. This is reflected in the current lack of specific legislation in most countries worldwide, whereby beekeeping is considered to be beneficial and is usually allowed in nature reserves and other types of protected areas, including some National Parks. In many cases, beekeeping in these areas is not only allowed but even promoted as a traditional, sustainable activity (information obtained from natural park and wildlife managers from 8 European countries, see acknowledgements). It is therefore not surprising that $A$. mellifera is routinely reported as a dominant species in plant-pollinator networks worldwide, even in studies conducted in natural habitats (Forup et al. 2008, Bosch et al. 2009, Kaiser-Bunbury et al. 2009, Valido et al. 2014; see Davila \& Wardle 2008 for a rare exception). However, as in other kinds of animal husbandry, large apiaries resulting in high densities of foragers may have an impact on local 
flower-visiting insects. Because they live in large colonies comprising tens of thousands of individuals and because they maintain elevated hive temperatures even during the winter (Seeley, 1985), honey bees have high energetic requirements, and their foraging ranges span several kilometres (Visscher \& Seeley, 1982). In addition, honey bees have the ability (unique to them and some stingless bees) to communicate the location of flower resources to nest mates, thus concentrating large numbers of foragers in highly rewarding patches (von Frisch, 1967). Thus, honey bees are highly efficient pollen-nectar foragers and, when present in large densities, may potentially create a competition scenario with other pollinators.

Competition may take place through interference or through resource exploitation (Tilman, 1982). Interference competition occurs directly between individuals through aggressive encounters (e.g., honey bees chasing other pollinators out of a flower or flower patch). Such aggressive interactions have sometimes been observed (e.g. Pinkus-Rendon et al. 2005), but the fact that most studies do not report aggressive encounters indicates that they are not common (e.g. Roubik 1978, Hudewenz \& Klein 2013). After several years of field work, we can assert that such interactions are very rare in our study area. Exploitative competition occurs indirectly between individuals through a limiting resource, such as food or nesting sites.

Competition for nesting resources can be ruled out in this case because wild bees in temperate zones do not nest in the kind of large cavities used by honey bees, and because feral colonies are very rare in our study area, as in most of Europe (Jaffé et al., 2009). Competition for flower resources is much more likely to occur because honey bees are highly generalistic in pollen and nectar use, and their diet widely overlaps with that of other flower-visiting species.

Various studies have explored potential adverse effects of honey bees on local pollinator communities. However, demonstrating a competition scenario is extremely difficult owing to the large foraging ranges of honey bees (several km) (Goulson, 2003; Seeley, 1985), combined with their ability to communicate the location of rich flower patches, thus allowing colonies to adjust their foraging areas and flower choices as pollen-nectar standing crops vary through time and space (Visscher \& Seeley, 1982). For this reason, most studies have so far focused on indirect evidences of competition between honey bees and wild bees, such as resource overlap 
107 (Steffan-Dewenter \& Tscharntke, 2000), changes in flower choice (Forup \& Memmott, 2005;

108 Valido et al., 2014), foraging activity (Thomson, 2004), and visitation rates (Hudewenz \& Klein, 109 2013; Roubik, 1978) of wild pollinators confronted with different honey bee scenarios. Other

110 studies have measured changes in population abundance and richness of wild bees under

111 different honey bee densities (Forup \& Memmott, 2005; Roubik \& Wolda, 2001; Roubik, 1978;

112 Steffan-Dewenter \& Tscharntke, 2000). Fewer studies have looked for more direct evidence of 113 competition, such as changes in reproductive success (Elbgami, Kunin, Hughes, \& Biesmeijer,

114 2014; Goulson \& Sparrow, 2009; Steffan-Dewenter \& Tscharntke, 2000; Thomson, 2004), and

115 the outcomes of these studies are not consistent. Some have found negative effects of honey

116 bees (Goulson \& Sparrow, 2009; Thomson, 2004) while others have not (Roubik \& Wolda,

117 2001; Steffan-Dewenter \& Tscharntke, 2000).

118

For exploitative competition to occur, floral resources should be limiting. However, to our knowledge, no study has hitherto measured the effects of honey bee abundance on pollen and nectar availability. This is important because we currently do not know the magnitude of the impact of honey bees on flower resources compared to resident pollinators. In this study we address the potential effects of beekeeping on wild bee communities in an environmentally protected natural area. Our objective is to study the impact of honey bee flower visitation on pollen and nectar consumption and the effect of beekeeping on the abundance, richness and composition of the local wild bee community. Because honey bees are very abundant and given their ability to recruit large numbers of foragers to the most rewarding flower patches, we have three hypotheses: (1) Honey bees will be the main contributors to flower resource consumption. We therefore expect pollen and nectar levels to be lower in areas close to apiaries; (2) Structure of the wild bee community will be modified by high honey bee densities. We expect wild bee richness and abundance to be lower close to apiaries; (3) Among wild bees, we expect large species (with higher feeding requirements; Müller et al., 2006), to be most affected.

\section{Study area}


138 This study was conducted in the Natural Park of el Garraf (Barcelona, Catalonia, NE Spain), a

139 Mediterranean scrubland dominated by Quercus coccifera, Pistacia lentiscus, Rosmarinus

140 officinalis and Thymus vulgaris. Over the last years, we identified 64 entomophilous plant

141 species and 288 insect pollinator species in the park.

143 The Natural Park of el Garraf is classified as category V of the International Union for

144 Conservation of Nature (IUCN) (Dudley, 2008), which includes the majority (62\%) of the

145 environmentally protected land in the Mediterranean region (López Ornat, Pons Reynés, \&

146 Noguera, 2007). Category $\vee$ parks are defined as protected areas with an important biological,

147 ecological, cultural and picturesque value based on the interaction between human populations

148 and the environment via traditional management practices. In Catalonia, current policies

149 regulating environmental impacts of human activities do not mention beekeeping (Law 20/2009,

150 DOGC 5524). Rather, beekeeping is considered an innocuous activity and $A$. mellifera is

151 declared a "species of special interest" (Decree 110/2003, DOGC 3870).

152

153 Our study area is entirely located in the park, encompassing a surface of $32 \mathrm{~km}^{2}$. We selected

15421 plots of $40 \mathrm{~m} \times 40 \mathrm{~m}$ distributed more or less regularly across the study area. Distances

155 between nearest plots ranged from 585 to $1354 \mathrm{~m}$. Based on the information provided by the

156 Department of Agriculture and subsequently verified in situ, we located 21 apiaries close to the

157 study area for a total of 475 hives (see Appendix A). Minimum distance of our plots to the

158 nearest apiary ranged from $262 \mathrm{~m}$ to $5122 \mathrm{~m}$.

159

160

Flower resource surveys

161

162 To study flower resource consumption, we worked on rosemary (Rosmarinus officinalis) and

163 thyme (Thymus vulgaris). These two species are, by far, the most abundant entomophilous

164 species in the study area, producing $70-90 \%$ of the flowers in the scrubland (Bosch et al., 2009;

165 Flo, 2014). In addition, the two species are very attractive to honey bees and are considered

166 highly desirable for honey production (Bonet, Rita, \& Sebastià, 1985; Cambra, 2008). In addition 
167

to honey bees, rosemary and thyme attract a variety of other pollinators. We have recorded 46 and 47 species visiting rosemary and thyme, respectively (Bosch et al. 2009). Of these,13 and 17 species are wild bees, including some early-flying Andrena ( $A$. angustior, A. nigroaenea) and Anthophora (A. acervorum, A. dispar) that concentrate most of their foraging on these two plant species. All surveys were conducted in 2011 under fair weather.

Pollen

Rosemary pollen surveys were conducted in March, when the species was in full bloom. In each plot, we selected between 20 and 30 plants on which we marked 8 recently-opened flowers (with fresh, fully pollen-loaded stamens). Before the onset of pollinator activity (9:00), we collected 4 of the marked flowers per plant, and stored them together in a vial filled with ethanol $70 \%$. After 18:00, when foraging activity had ceased, the remaining 4 flowers per plant were collected and preserved following the same procedure.

Thyme pollen surveys were conducted in April, during peak bloom of this species. We selected between 20 and 30 thyme plants per plot and marked 4 recently-opened flowers in each of them, following the same criteria as for rosemary. Before 9:00 we collected the two stamens of one side (left or right) of each flower, and stored them together in a vial filled with ethanol $70 \%$. After 18:00 we collected the two remaining stamens of each flower.

In the laboratory, vials with stamens were sonicated for 10 minutes in an ultrasonic bath to dislodge pollen grains from the anthers. Afterwards, each anther was inspected under the stereomicroscope and pollen grains still adhering to the anthers were manually detached with the aid of an insect pin. Later, we took 8 drops of $2.5 \mu$ of the resulting pollen suspension and counted the number of pollen grains under the stereomicroscope. Previous trials showed that the number of drops necessary to stabilize pollen counts was 6 . We then measured the remaining ethanol volume in the vial, and estimated the total number of pollen grains in each sample. From these data, we estimated the number of pollen grains per flower in the morning 
200

and in the evening, which we used to calculate pollen consumption. Overall, we sampled 4005 rosemary flowers and 2366 thyme flowers.

Nectar

Nectar consumption is difficult to measure because nectar secretion is a more or less continuous process (Pacini, Nepi, \& Vesprini, 2003), so that consumption may be compensated by subsequent secretion. In some cases, secretion may be even stimulated by consumption (Castellanos, Wilson, \& Thomson, 2002; Ordano \& Ornelas, 2004). In addition, nectar secretion can be strongly conditioned by weather conditions (Jakobsen \& Kristjánsson, 1994; Petanidou \& Smets, 1996). We therefore decided to measure nectar standing crops at the end of the day as a surrogate for nectar consumption.

Thyme flowers produce very small amounts of nectar (Arnan, Escolà, Rodrigo, \& Bosch, 2014), which may become difficult to extract, especially in warm dry days. For this reason, nectar surveys were only conducted on rosemary. At the end of each sampling day, we used 1- $\mu$ l capillary tubes to measure the volume of nectar remaining in the flowers. This was done on most of the flowers used in the evening pollen surveys. We measured nectar standing crops in 1628 rosemary flowers (mean number of flowers per plot $=86$; range $=33-117$ ).

\section{Pollinator visitation rates}

To relate pollen and nectar consumption to pollinator activity, we conducted pollinator surveys between 9:00 and 18:00 in each plot on the same day in which pollen and nectar measures were taken. At each plot, we selected 10 rosemary and 10 thyme plants. These plants were not the same used in pollen/nectar surveys to avoid potential accidental contact with flowers marked for pollen-nectar measures. On each marked plant we conducted a number of pollinator counts (mean $=10$, range $=5-15$ ) throughout the day. In each count, the selected plant was observed for 2 minutes and all pollinators contacting flowers were recorded. Total observation time was $72 \mathrm{~h} 48 \mathrm{~min}$ for rosemary and $76 \mathrm{~h} 34 \mathrm{~min}$ for thyme. At the end of the day, we 
counted the number of open flowers in each plant. Apis mellifera and the bumblebee Bombus terrestris were, by far, the two most frequent pollinators visiting the two plant species. Therefore, we grouped pollinators into three categories: A. mellifera, B. terrestris, and other pollinators (mostly other bees, along with some dipterans and a few lepidopterans and coleopterans). Visitation rates of each pollinator group were calculated as the number of contacts per minute and per 1000 flowers.

\section{Bee community}

To assess bee community structure and composition, we placed 6 sampling stations in each plot. Each sampling station consisted of a metal bar holding 3 pan traps painted yellow, white and blue respectively, one metre above the ground (Westphal et al. 2008). We conducted 8 biweekly surveys from mid-March to late June 2010, in which traps were set at 8:00-9:00, before the onset of pollinator activity (around 9:30) and collected after 18:00. All plots were sampled on the same 8 days (see Torné-Noguera et al. (2014) for details). We captured 6580 bee specimens, which were dried and pinned for identification. In addition, we netted and weighed a few individuals of each species/sex to obtain measures of fresh body weight $(n=1-52$ specimens per species). Species were subsequently classed as small (body weight $<55 \mathrm{mg}$ ) or large (>70 mg) (see Torné-Noguera et al. (2014) for details).

\section{Flower abundance}

To estimate flower abundance in each plot, we considered the main flowering species in the scrubland (R. officinalis, T. vulgaris, Dorycnium pentaphyllum, Cistus albidus, Cistus salvifolius and Cistus monspeliensis), which together accounted for $>70 \%$ of the flowers in each plot. We measured two perpendicular widths and the height of each flower patch in two $40 \times 1 \mathrm{~m}$ perpendicular transects centered in the middle of the plot. Then we estimated the number of flowers of each species based on previously established equations relating patch volume and number of open flowers at peak bloom $\left(r^{2}=0.36-0.63, p=0.001-0.015\right)$ (see Torné-Noguera et al., 2014). Because the three Cistus species were much less abundant than the other species, 
and their flowering periods largely overlap, we lumped together these three species into a single category (Cistus abundance).

258

\section{Statistical analysis}

260

Visitation rates and pollen/nectar consumption

262

Preliminary analyses showed no correlation between explanatory variables (visitation rates of the different pollinator groups). In pollen analysis, honey bee visitation rate and other pollinators visitation rate were log-transformed because there was a logarithmic relationship between these variables and pollen consumption. We initially fit a generalized linear model (GLM) assuming a binomial error distribution (adequate for proportion data such as pollen consumption), with $A$. mellifera visitation rate, Bombus terrestris visitation rate, and other pollinators visitation rate as predictive variables. However, the model showed overdispersion. Therefore, we finally opted for a quasibinomial GLM. We then compared the saturated model with the various non-saturated models and chose the best one using ANOVA (as AIC cannot be calculated for quasi model families). Finally, we checked for normality and homoscedasticity of the residuals. We used pseudo- $R^{2}$ as a measure of the goodness-of-fit.

In nectar analyses, we log-transformed the explanatory variable other pollinators visitation rate because it showed a logarithmic relationship with the response variable. We fit a generalized linear model (GLM) with a Gaussian error distribution, with nectar standing crop as the response variable and visitation rate of the various pollinator groups as predictive variables. We selected the best model using the second-order Akaike Information Criterion (AICc), adequate for small samples. 
We used MiraMon SIG software (Pons, 2014) to establish the linear distance of each plot to the nearest apiary, a measure commonly used in honey bee studies (Elbgami et al., 2014; Hudewenz \& Klein, 2013; Steffan-Dewenter \& Tscharntke, 2000; Thomson, 2004).

287

To evaluate the potential relationship between distance to the nearest apiary and wild bee community structure, we run GLM models for wild bee abundance, wild bee richness and wild bee biomass. Because wild bee community structure may also be influenced by flower availability (Torné-Noguera et al., 2014), we included flower abundance of $T$. vulgaris, $R$. officinalis, D. pentaphyllum and Cistus as predictor variables. Correlations between predictor variables were low (ranging from -0.27 to 0.33 ) and non-significant. We did not include nesting substrate availability in the analysis because we know from previous studies that this is not a good predictor of bee community structure and composition in the study area (Torné-Noguera et heteroscedasticity-corrected covariance matrices to make inference.

307

All analyses were computed with R (R Core Team, 2014).

309

Results 
Apis mellifera and B. terrestris accounted for the majority of visits to both rosemary (61.2 and $30.1 \%$, respectively) and thyme (39.5 and $34.8 \%)$. Visits of other pollinators amounted to 8.7 and $25.7 \%$ of the visits to rosemary and thyme, respectively. Honey bee flower visits and bumblebee flower visits were not correlated (rosemary: $\mathrm{T}=0.23, p=0.16$; thyme: $\mathrm{T}=0.04, p=$ 0.83). Honey bee visitation rate showed a negative relationship with distance to the nearest apiary $\left(r^{2}=42.25, p=0.009\right)$.

Mean \pm SE number of pollen grains in newly-opened rosemary flowers was $5185 \pm 70$, and these numbers decreased to $1831 \pm 68$ by the end of the day. Pollen consumption in our plots ranged from $25.1 \%$ to $90.1 \%$ (mean \pm SE $=65.6 \pm 4.0$ ). The best model for rosemary pollen consumption (pseudo- $\left.R^{2}=0.54\right)$ included $A$. mellifera visitation rate $(p=0.004)$ and, marginally, B. terrestris visitation rate $(p=0.06)($ Fig. $1 A$ and $B)$.

Thyme flowers contained $1220 \pm 30$ pollen grains in the morning and $577 \pm 18$ at the end of the day. Thyme pollen consumption in the various plots ranged between $19.2 \%$ and $76.5 \%$ (mean \pm $\mathrm{SE}=54.3 \pm 3.5$ ). The best model for thyme pollen consumption (pseudo- $\mathrm{R}^{2}=0.42$ ) included $A$. mellifera visitation rate $(p=0.002)$ and B. terrestris visitation rate $(p=0.04)$ (Fig. $1 C$ and $D)$.

Rosemary nectar standing crops in the 21 plots ranged from 0 to $6.31 \mu \mathrm{L} /$ flower $(0.26 \pm 0.39)$.

The best model explaining rosemary nectar levels (pseudo- $R^{2}=0.42$ ) included $A$. mellifera visitation rate $(p=0.04)$ and, marginally, $B$. terrestris visitation rate $(p=0.05)($ Fig. 2$)$.

\section{Bee community}

Pan trap surveys yielded 6580 bee specimens corresponding to 98 species. Sixty-three of the non-Apis species were small (fresh body weight $<55 \mathrm{mg}$ ) and 34 were large ( $>70 \mathrm{mg}$ ). Honey bee abundance in the pan traps was negatively related to distance to the nearest apiary (logarithmic relationship, $\left.r^{2}=49.73, p=0.0004\right)$. 
No variables entered the model of wild bee richness (Table 1), and similar results were obtained

360 when small and large bees were analyzed separately (Table 1). The best model for bee abundance (pseudo- $\left.\mathrm{R}^{2}=0.48\right)$ included Cistus flower abundance $(\mathrm{p}=0.002)$ and $T$. vulgaris flower abundance $(p=0.004)$. Similar results were obtained when only small bees were taken into account (pseudo- $R^{2}=0.41$; Cistus abundance $(p=0.008) ; T$. vulgaris abundance $\left.(p=0.03)\right)$. Instead, the best fit model for large bee abundance (pseudo- $R^{2}=0.50$ ) included distance to the nearest apiary $(p=0.02)$ and, marginally, Cistus abundance $(p=0.06)$ (Fig. 3A and B; Table 1). To be conservative, we re-ran the latter analysis without 3 possible leverage points (Cook's $D=$ 0.5 to 1 ), and obtained similar results with a lower goodness-of-fit (pseudo- $R^{2}=0.28$, distance to the nearest apiary $p=0.02$, Cistus abundance $p=0.06$ ). The best wild bee biomass model (pseudo- $\left.\mathrm{R}^{2}=0.56\right)$ included Cistus flower abundance $(\mathrm{p}=0.002)$ along with distance to the nearest apiary $(p=0.02)$. The best model for small bees (pseudo- $R^{2}=0.27$ ) included only Cistus abundance $(p=0.02)$ (Table 1). Conversely, the best model for large bees (pseudo- $\left.R^{2}=0.54\right)$ included distance to the nearest apiary $(p=0.007)$ and, marginally, Cistus abundance $(p=0.06)$ (Fig. 3C and D).

\section{Discussion}

Honeybees outnumbered the most frequent wild bee (the bumblebee $B$. terrestris) on rosemary and thyme flowers, the two main flowering plants in the study area. All workers of these two bee species collected nectar, and some of them also collected pollen. Our results demonstrate that honey bees were the main species contributing to pollen and nectar consumption. The contribution of $B$. terrestris was much lower, and other pollinators played a non-detectable role in flower resource consumption. In addition to being the most frequent visitors to rosemary and thyme, $A$. mellifera and $B$. terrestris visit more flowers per individual plant than other pollinators (Arnan et al., 2014). Mean pollen consumption per plot was slightly higher for rosemary (mean= $65.6 \%$, range $=25.1-90.1 \%)$ than for thyme (mean $=54.3 \%$, range $=19.2-76.5 \%$ ), but to a greater or lesser extent, most plots had considerable amounts of pollen and nectar available at the end of the day. This may suggest that flower resources are not a limiting factor for the bee community. However, the energetic gain obtained from flowers with pollen-nectar levels below a 
certain threshold may be insufficient to compensate foraging costs, especially for large bees, with higher energetic demands (Heinrich, 1975). Bees have been shown to move away from less rewarding patches (Heinrich, 1979). Our pollen-nectar surveys were conducted during peak bloom of the two main flower species in the study area. By the end of April, flower resources are much scarcer in the Park, and overall visitation rates are much higher (Bosch et al., 2009; Filella et al., 2013; Flo, 2014). Consequently, we expect the potential effects of intensive honey bee foraging to be greater in late-spring. In the summer, when floral resources in the Park are very low, some beekeepers move their hives to mountain areas.

381

382 Our study also shows that the wild bee community is affected and modified in areas close to apiaries, with a lower overall wild bee biomass mediated by a lower abundance of large bees. Small bees require less energy to fly and sustain foraging and nesting activities (Heinrich 1975). In addition, small bees require smaller pollen/nectar amounts to produce an offspring (Müller et al., 2006). Thus, pollen and nectar standing crops in areas close to the apiaries may be sufficient for small bees but not for large bees. If so, large bees may be forced to nest somewhere else or widen their foraging ranges, which are well known to be positively related to body size (Gathmann \& Tscharntke, 2002; Greenleaf, Williams, Winfree, \& Kremen, 2007; Guédot, Bosch, \& Kemp, 2009). As for small bees, even if their abundance did not diminish close to apiaries, their fitness might still be affected by the lower pollen/nectar standing crops. At the intra-specific level, bee adult body size is directly related to the amount of pollen-nectar consumed by the larva (Bosch \& Vicens, 2002; Ribeiro, 1994), and some studies have shown reductions in offspring body size in populations flying in areas with low levels of flower resources (Bosch, 2008; Peterson \& Roitberg, 2006). Other studies have found that bumblebee colonies produce smaller workers in areas with managed honey bees, probably due to pollen/nectar scarcity (Elbgami et al., 2014; Goulson \& Sparrow, 2009). Small offspring are more likely to die during development (Bosch, 2008) and during wintering (Bosch \& Kemp, 2004; Tepedino \& Torchio, 1982). Smaller females are also less likely to found a nest (Bosch \& Vicens, 2006; Tepedino \& Torchio, 1982). Low levels of floral resources may also enhance parasitism in solitary bees (Goodell, 2003), as females are forced to make longer foraging trips 
403

(Seidelmann, 2006). In agreement with our results, some studies investigating the potential impact of honey bees on wild bee communities have found wild bee abundance to be lower near apiaries (Forup \& Memmott, 2005; Thomson, 2006), but others have not (Roubik \& Wolda, 2001; Steffan-Dewenter \& Tscharntke, 2000). On the other hand, and in agreement with other studies (Forup \& Memmott, 2005; Roubik \& Wolda, 2001; Steffan-Dewenter \& Tscharntke, 2000), bee richness was not influenced by proximity to apiaries in our study.

In addition to honey bee density, bee abundance and biomass may also be influenced by flower abundance and distribution. Our models show that Cistus flowers have an important role in structuring the Garraf bee community. The three Cistus species occurring in the park bloom in April, at a time when wild bee abundance and diversity are high, and flower resources show a strong decline after the blooming period of $R$. officinalis and T. vulgaris (Bosch et al., 2009; Filella et al., 2013; Flo, 2014). Other plants blooming at this time are either very scarce (Gladiolus illyricus, Orobanche latisquama), or produce smaller amounts of pollen and nectar (D. penthaphyllum) (Flo, 2014). Previous studies in the same area have shown that C. albidus and C. salvifolius constitute a hub in the Garraf pollination network, attracting higher numbers of pollinator species and receiving higher flower visitation rates than any other plant species (Bosch et al., 2009).

Our study provides evidence to support the hypothesis that high densities of managed honey bees have a negative impact on wild bee communities. Our results point to pollen-nectar depletion as a mechanism explaining this negative impact. To our knowledge, this is the first time flower resource consumption has been measured in studies exploring the potential effects of managed honey bees on wild pollinators. To confirm or refute this hypothesis, future studies should include long-term monitoring of wild bee populations and direct measures of fitness. From a land management perspective, decisions on the number of hives allowed in an environmentally protected area should be based on the carrying capacity of the flower community at the landscape level. However, to provide a range of appropriate hive densities is extremely difficult for several reasons. First, even in a natural habitat such as the Garraf Natural Park, flower spatial distribution is far from homogeneous (Torné-Noguera et al., 2014). Second, 
availability of flower resources in our study area changes dramatically throughout the season and from year to year (Flo, 2014). Third, foraging ranges of honey bees span several kilometers and are highly variable in time (Visscher \& Seeley, 1982). Fourth, resource depletion may also depend on the abundance of wild pollinator populations. Given all these uncertainties, our study suggests that, in this particular habitat, wild bee communities are likely to be affected at densities over 3.5 hives per $\mathrm{km}^{2}$ (475 hives / $134 \mathrm{~km}^{2}$ ).

\section{Epilogue}

The Garraf Natural Park is partially located in the municipality of Olivella. In May 2012, the city council discussed a petition to install 357 new honey bee hives in the Park. The council examined a report commissioned by the board of directors of the Park cautioning about the potential effects of intensive beekeeping on other pollinators. The council finally approved the installation of the additional 357 hives based on current legislation considering beekeeping an "innocuous activity".

\section{Acknowledgements}

We are thankful to H. Barril-Graells, I. Raya, O. Riera, S. Reverté, P. Cucurull, M. A. Requesens, I. Doncel, J. Prat, A. Lázaro, A. Revoltós, J. P. Vilellas, N. Mas, M. Viladés, A. Llavina, A. López, D. González, and L. Muñoz for their help with field and laboratory work, and to M. Fernández for his statistical advice. D. Duggan (DAHG, Ireland), H. Haller (Schweizerische Nationalpark, Switzerland), M. Heinonen (Metsähallitus, Finland), A. Korakis (Pindos National Park, Greece), J. Lannek (Jordbruksverket, Sweden), L. Pelle (Parco Nazionale dell'Aspromonte, Italy), J. Torrentó (Diputació de Barcelona, Spain) and H. P. Vicente (ICNF, Portugal) kindly provided information on beekeeping legislation in their respective countries. This study was supported by the Spanish Ministry of Science and Innovation (MICINN, projects CGL2005-00491, CGL2009-12646 and CSD2008-0040); and an FPI fellowship (BES-2010-042520) to A.T-N.; and by Diputació de Barcelona. S.O. was supported by a FI fellowship (2012 FI SO080484) from Generalitat de Catalunya. 
Appendix A. Supplementary data

465

Supplementary data associated with this article can be found, in the online version, at XXXXX.

467

References

469

Aizen, M. A., \& Harder, L. D. (2009). The global stock of domesticated honey bees is growing slower than agricultural demand for pollination. Current Biology, 19(11), 915-918. doi:10.1016/j.cub.2009.03.071

Arnan, X., Escolà, A., Rodrigo, A., \& Bosch, J. (2014). Female reproductive success in

Bonet, A., Rita, J., \& Sebastià, M. T. (1985). La flora mel-lifera de la circumscripció de gynodioecious Thymus vulgaris: Pollen versus nutrient limitation and pollinator foraging behaviour. Botanical Journal of the Linnean Society, 175, 395-408. doi:10.1111/boj.12173

Bosch, J. (2008). Production of undersized offspring in a solitary bee. Animal Behaviour, 75(3), Barcelona. Diputació de Barcelona.

Bosch, J., \& Kemp, W. P. (2004). Effect of pre-wintering and wintering temperature regimes on

Bosch, J., Martín González, A. M., Rodrigo, A., \& Navarro, D. (2009). Plant-pollinator networks: adding the pollinator's perspective. Ecology Letters, 12(5), 409-19. doi:10.1111/j.14610248.2009.01296.x

Bosch, J., \& Vicens, N. (2002). Body size as an estimator of production costs in a solitary bee. 
Bosch, J., \& Vicens, N. (2006, December 16). Relationship between body size, provisioning rate, longevity and reproductive success in females of the solitary bee Osmia cornuta. Behavioral Ecology and Sociobiology. doi:10.1007/s00265-005-0134-4

Breeze, T. D., Vaissière, B. E., Bommarco, R., Petanidou, T., Seraphides, N., Kozák, L., ... Potts, S. G. (2014). Agricultural policies exacerbate honeybee pollination service supplydemand mismatches across Europe. PLoS ONE, 9(1). doi:10.1371/journal.pone.0082996

Byers, J. E. (2000). Competition between two estuarine snails: implications for invasions of exotic species. Ecology, 81(5), 1225-1239. doi:10.1890/00129658(2000)081[1225:CBTESI]2.0.CO;2

Cambra, J. (2008). Flora mel-lífera de Catalunya. In Apicultura i producció de mel a Catalunya. Dossier tècnic. (p. 20). Generalitat de Catalunya. Departament d'Agricultura, Alimentació i Acció Rural.

Castellanos, M. C., Wilson, P., \& Thomson, J. D. (2002). Dynamic nectar replenishment in flowers of Penstemon (Scrophulariaceae). American Journal of Botany, 89(1), 111-118. doi:10.3732/ajb.89.1.111

Crane, E. (1990). Bees and beekeeping: science, practice and world resources. Oxford, UK: Heinemann Newnes.

Davila, Y. C., \& Wardle, G. M. (2008). Variation in native pollinators in the absence of honeybees: implications for reproductive success of an Australian generalist-pollinated herb Trachymene incisa (Apiaceae). Botanical Journal of the Linnean Society, 156, 479490. doi:10.1111/j.1095-8339.2007.00774.x

Dudley, N. (2008). Guidelines for applying protected area management categories. (N. Dudley, Ed.). Gland, Switzerland: IUCN.

Ehrenfeld, J. G. (2010). Ecosystem consequences of biological invasions. Annual Review of Ecology, Evolution, and Systematics, 41(1), 59-80. doi:10.1146/annurev-ecolsys-102209144650 
Elbgami, T., Kunin, W. E., Hughes, W. O. H., \& Biesmeijer, J. C. (2014). The effect of proximity to a honeybee apiary on bumblebee colony fitness, development, and performance. Apidologie, 45(4), 504-513. doi:10.1007/s13592-013-0265-y

Filella, I., Primante, C., Llusià, J., Martín González, A. M., Seco, R., Farré-Armengol, G., ... Peñuelas, J. (2013). Floral advertisement scent in a changing plant-pollinators market. Scientific Reports, 3, 3434. doi:10.1038/srep03434

Flo, V. (2014). Eight-year variability in flowering patterns in a Mediterranean scrubland community: consequences on pollen-nectar composition. MSc Thesis. Autonomous University of Barcelona.

Forup, M. L., Henson, K. S. E., Craze, P. G., \& Memmott, J. (2008). The restoration of ecological interactions: plant-pollinator networks on ancient and restored heathlands. Journal of Applied Ecology, 45(3), 742-752. doi:10.1111/j.1365-2664.2007.01390.x

Forup, M. L., \& Memmott, J. (2005). The relationship between the abundances of bumblebees and honeybees in a native habitat. Ecological Entomology, 30(1), 47-57. doi:10.1111/j.0307-6946.2005.00660.x

Free, J. B. (1993). Insect pollination of crops. Academic Press, London.

Garibaldi, L. A., Steffan-Dewenter, I., Winfree, R., Aizen, M. A., Bommarco, R., Cunningham, S. A., ... Klein, A. M. (2013). Wild pollinators enhance fruit set of crops regardless of honey bee abundance. Science, 339(6127), 1608-11. doi:10.1126/science.1230200

Gathmann, A., \& Tscharntke, T. (2002). Foraging ranges of solitary bees. Journal of Animal Ecology, 71(5), 757-764. doi:10.1046/j.1365-2656.2002.00641.x

Goodell, K. (2003). Food availability affects Osmia pumila (Hymenoptera: Megachilidae) foraging, reproduction, and brood parasitism. Oecologia, 134(4), 518-27. doi:10.1007/s00442-002-1159-2 
Goulson, D. (2003). Effects of introduced bees on native ecosystems. Annual Review of Ecology, Evolution, and Systematics, 34(1), 1-26. doi:10.1146/annurev.ecolsys.34.011802.132355

Goulson, D., \& Sparrow, K. R. (2009). Evidence for competition between honeybees and bumblebees; effects on bumblebee worker size. Journal of Insect Conservation, 13(2), 177-181. doi:10.1007/s10841-008-9140-y

Greenleaf, S. S., Williams, N. M., Winfree, R., \& Kremen, C. (2007). Bee foraging ranges and their relationship to body size. Oecologia, 153(3), 589-96. doi:10.1007/s00442-007-07529

Guédot, C., Bosch, J., \& Kemp, W. P. (2009). Relationship between body size and homing ability in the genus Osmia (Hymenoptera; Megachilidae). Ecological Entomology, 34(1), 158-161. doi:10.1111/j.1365-2311.2008.01054.x

Heinrich, B. (1975). Energetics of pollination. Annual Review of Ecology and Systematics, 6, 139-170. doi:10.1146/annurev.es.06.110175.001035

Heinrich, B. (1979). Resource heterogeneity and patterns of movement in foraging bumblebees. Oecologia, 40, 235-245. doi:10.1007/BF00345321

Hudewenz, A., \& Klein, A.-M. (2013). Competition between honey bees and wild bees and the role of nesting resources in a nature reserve. Journal of Insect Conservation, 17(6), 12751283. doi:10.1007/s10841-013-9609-1

Jaffé, R., Dietemann, V., Allsopp, M. H., Costa, C., Crewe, R. M., Dall'Olio, R., ... Moritz, R. F. A. (2009). Estimating the density of honeybee colonies across their natural range to fill the gap in pollinator decline censuses. Conservation Biology, 24(2), 583-93. doi:10.1111/j.1523-1739.2009.01331.x

Jakobsen, H. B., \& Kristjánsson, K. K. (1994). Influence of temperature and floret age on nectar secretion in Trifolium repens L. Annals of Botany, 74, 327-334. doi:10.1006/anbo.1994.1125 
Kaiser-Bunbury, C. N., Memmott, J., \& Müller, C. B. (2009). Community structure of pollination webs of Mauritian heathland habitats. Perspectives in Plant Ecology, Evolution and Systematics, 11(4), 241-254. doi:10.1016/j.ppees.2009.04.001

Levine, J. M., Vilà, M., D’Antonio, C. M., Dukes, J. S., Grigulis, K., \& Lavorel, S. (2003). Mechanisms underlying the impacts of exotic plant invasions. Proceedings. Biological Sciences / The Royal Society, 270(1517), 775-81. doi:10.1098/rspb.2003.2327

López Ornat, A., Pons Reynés, A., \& Noguera, M. (2007). Use of IUCN protected areas management categories in the Mediterranean region. (A. López Ornat, A. Pons Reynés, \& M. Noguera, Eds.). Consejería de Medio Ambiente of Junta de Andalucía, Sevilla, Spain and IUCN, Gland, Switzerland and Malaga, Spain.

Müller, A., Diener, S., Schnyder, S., Stutz, K., Sedivy, C., \& Dorn, S. (2006). Quantitative pollen requirements of solitary bees: Implications for bee conservation and the evolution of beeflower relationships. Biological Conservation, 130(4), 604-615. doi:10.1016/j.biocon.2006.01.023

Ordano, M., \& Ornelas, J. F. (2004). Generous-like flowers: nectar production in two epiphytic bromeliads and a meta-analysis of removal effects. Oecologia, 140(3), 495-505. doi: $10.1007 / \mathrm{s} 00442-004-1597-0$

Pacini, E., Nepi, M., \& Vesprini, J. L. (2003). Nectar biodiversity: A short review. Plant Systematics and Evolution, 238, 7-21. doi:10.1007/s00606-002-0277-y

Petanidou, T., \& Smets, E. (1996). Does temperature stress induce nectar secretion in Mediterranean plants? New Phytologist, 133(3), 513-518. doi:10.1111/j.14698137.1996.tb01919.x

Peterson, J. H., \& Roitberg, B. D. (2006). Impacts of flight distance on sex ratio and resource allocation to offspring in the leafcutter bee, Megachile rotundata. Behavioral Ecology and Sociobiology, 59(5), 589-596. doi:10.1007/s00265-005-0085-9 
589

590

591

592

593

594

595

596

597

598

599

600

601

602

603

604

605

606

607

608

609

610

611

612

613

Petren, K., \& Case, T. J. (1996). An experimental demonstration of exploitation competition in an ongoing invasion. Ecology, 77(1), 118-132. doi:10.2307/2265661

Pinkus-Rendon, M. A., Parra-Tabla, V., \& Meléndez-Ramírez, V. (2005). Floral resource use and interactions between Apis mellifera and native bees in cucurbit crops in Yucatán, México. The Canadian Entomologist, 137(04), 441-449. doi:10.4039/n04-043

Pons, X. (2014). MiraMon. Geographic Information System and Remote Sensing Software. Geographical Information System and Remote Sensing Software. Barcelona: CREAF.

R Core Team. (2014). R: A language and environment for statistical computing. Vienna, Austria: R Foundation for Statistical Computing.

Ribeiro, M. F. (1994). Growth in bumble bee larvae: relation between development time, mass, and amount of pollen ingested. Canadian Journal of Zoology, 72(11), 1978-1985. doi:10.1139/z94-270

Roubik, D. W. (1978). Competitive interactions between neotropical pollinators and africanized honey bees. Science, 201, 1030-1032. doi:10.1126/science.201.4360.1030

Roubik, D. W., \& Wolda, H. (2001). Do competing honey bees matter? Dynamics and abundance of native bees before and after honey bee invasion. Population Ecology, 43(1), 53-62. doi:10.1007/PL00012016

Seeley, T. D. (1985). Honeybee ecology: a study of adaptation in social life. Princeton, New Jersey: Princeton University Press.

Seidelmann, K. (2006). Open-cell parasitism shapes maternal investment patterns in the Red Mason bee Osmia rufa. Behavioral Ecology, 17(July), 839-848. doi:10.1093/beheco/arl017

Steffan-Dewenter, I., \& Tscharntke, T. (2000). Resource overlap and possible competition between honey bees and wild bees in central Europe. Oecologia, 122(2), 288-296. doi:10.1007/s004420050034 
Stewart, K. M., Bowyer, R. T., Kie, J. G., Cimon, N. J., \& Johnson, B. K. (2002). Temporospatial distributions of elk, mule deer, and cattle: resource partitioning and competitive displacement. Journal of Mammalogy, 83(1), 229-244. doi:10.1644/15451542(2002)083<0229:TDOEMD>2.0.CO;2

Tepedino, V. J., \& Torchio, P. F. (1982). Phenotypic variability in nesting success among Osmia lignaria propinqua females in a glasshouse environment: (Hymenoptera: Megachilidae). Ecological Entomology, 7(4), 453-462. doi:10.1111/j.1365-2311.1982.tb00688.x

Thomson, D. M. (2004). Competitive interactions between the invasive European honey bee and native bumble bees. Ecology, 85(2), 458-470. doi:10.1890/02-0626

Thomson, D. M. (2006). Detecting the effects of introduced species: a case study of competition between Apis and Bombus. Oikos, 114(3), 407-418. doi:10.1111/j.2006.00301299.14604.x

Tilman, D. (1982). Resource competition and community structure. Princeton, New Jersey: Princeton University Press.

Torné-Noguera, A., Rodrigo, A., Arnan, X., Osorio, S., Barril-Graells, H., Correia da RochaFilho, L., \& Bosch, J. (2014). Determinants of spatial distribution in a bee community: nesting resources, flower resources, and body size. PLOS ONE, 9(5), e97255. doi:10.1371/journal.pone.0097255

Valido, A., Rodriguez-Rodriguez, M. C., \& Jordano, P. (2014). Impacto de la introducción de la abeja doméstica (Apis mellifera, Apidae) en el Parque Nacional del Teide (Tenerife, Islas Canarias). Ecosistemas, 23(3), 58-66.

Visscher, P. K., \& Seeley, T. D. (1982). Foraging strategy of honeybee colonies in a temperate deciduous forest. Ecology, 63(6), 1790-1801. doi:10.2307/1940121

Von Frisch, K. (1967). The dance language and orientation of bees. Harvard University Press. Cambridge, MA. 
639

640

641

642

643

644

645

Westphal, C., Bommarco, R., Carré, G., Lamborn, E., Petanidou, T., Potts, S. G., ... Vaissi, E. (2008). Measuring bee diversity in different European habitats and biogeographical regions. Ecological Monographs, 78(4), 653-671. doi:10.1890/07-1292.1

Young, T. P., Palmer, T. M., \& Gadd, M. E. (2005). Competition and compensation among cattle, zebras, and elephants in a semi-arid savanna in Laikipia, Kenya. Biological Conservation, 122(2), 351-359. doi:10.1016/j.biocon.2004.08.007

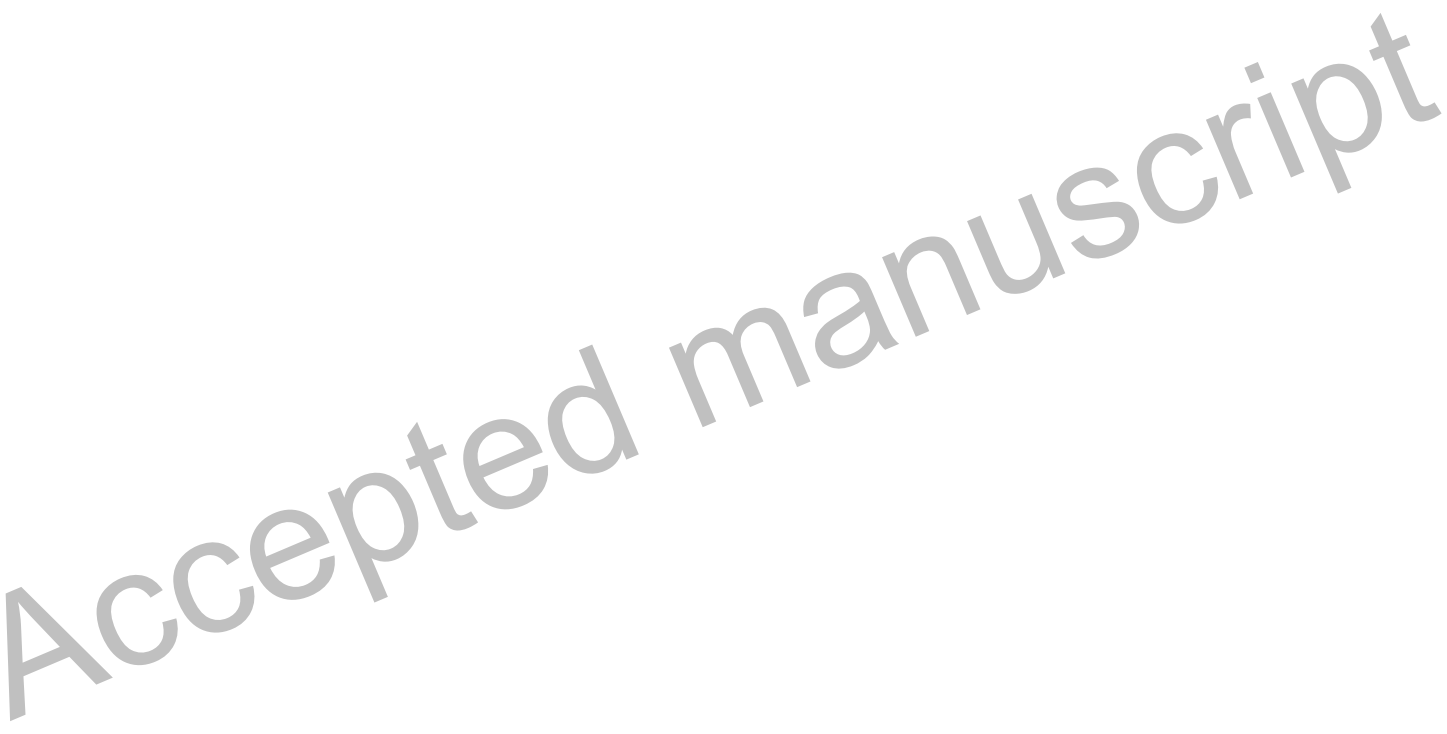


Table 1. Results of GLMs analyzing wild bee richness, abundance and biomass in 21 plots as a function of distance to the nearest apiary, and abundance of Cistus spp., Thymus vulgaris, Rosmarinus officinalis and Dorycnium pentaphyllum flowers. P-values are only given for variables entering the models. Pseudo-

$R^{2}$ is provided as a measure of goodness-of-fit.

\begin{tabular}{|c|c|c|c|c|c|c|c|}
\hline \multirow[t]{2}{*}{ Response variable } & & \multicolumn{5}{|c|}{ Explanatory variables } & \multirow[t]{2}{*}{ Pseudo- $\mathrm{R}^{2}$} \\
\hline & & Distance to apiary & Cistus & T. vulgaris & R. officir & taphyllum & \\
\hline \multirow[t]{3}{*}{ Wild bee richness } & Large species $^{1}$ & ns & ns & ns & & ns & -- \\
\hline & Small species ${ }^{2}$ & ns & ns & & ns & ns & -- \\
\hline & All species & ns & & ns & ns & ns & -- \\
\hline \multirow[t]{3}{*}{ Wild bee abundance } & Large species $^{1}$ & & $p=0.061$ & ns & ns & ns & 0.50 \\
\hline & Small species² & ns & $p=0.008$ & $p=0.030$ & ns & ns & 0.41 \\
\hline & All species & ns & $p=0.002$ & $p=0.042$ & ns & ns & 0.48 \\
\hline \multirow[t]{3}{*}{ Wild bee biomass } & Large species $^{1}$ & $p=0.007$ & $p=0.059$ & ns & ns & ns & 0.54 \\
\hline & Small species² & ns & $p=0.016$ & ns & ns & ns & 0.27 \\
\hline & All species & $p=0.017$ & $p=0.016$ & ns & ns & ns & 0.56 \\
\hline
\end{tabular}

${ }^{1}$ Body weight $>70 \mathrm{mg:}{ }^{2}$ Body weight $<55 \mathrm{mg}$. 
646 Fig.1. Partial regression plots showing the contribution of honey bee and bumblebee visitation

647 rates to rosemary and thyme pollen consumption in 21 plots, once the effect of other

648 explanatory variables entering the GLMs has been removed (bumblebee visitation rate in (A)

649 and (C); honey bee visitation rate in (B) and (D))

650

651 Fig. 2. Partial regression plots showing the contribution of honey bee and bumblebee visitation 652 rates to rosemary nectar standing crops in 21 plots, once the effect of other explanatory

653 variables entering the GLMs has been removed (bumblebee visitation rate in (A); honey bee

654 visitation rate in (B))

655

656 Fig. 3. Partial regression plots showing the relationship between distance to the nearest apiary 657 and large bee (body weight $>70 \mathrm{mg}$ ) abundance and biomass in 21 plots, once the effect of other explanatory variables entering the GLMs has been removed (Cistus flower abundance in

659 (A) and (C); distance to the nearest apiary in (B) and (D))

660 
661

662

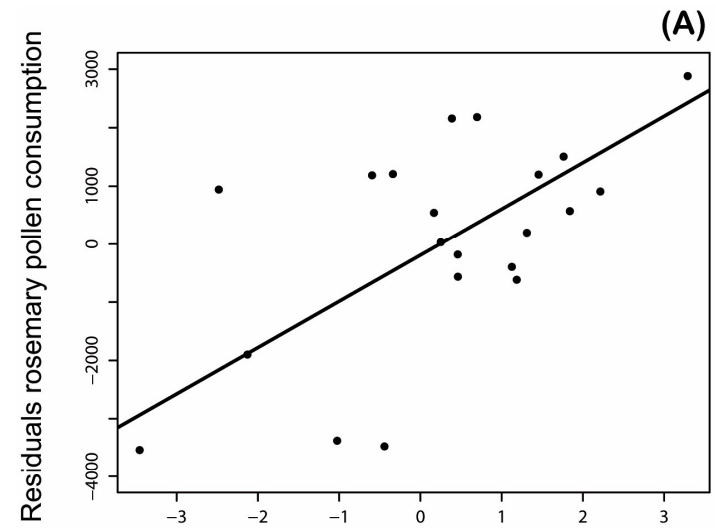

(C)

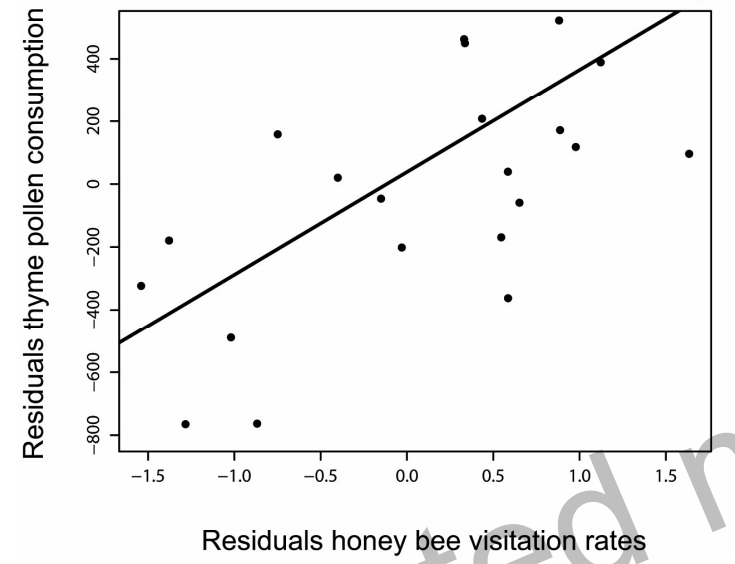

663

Fig.1.

(A)

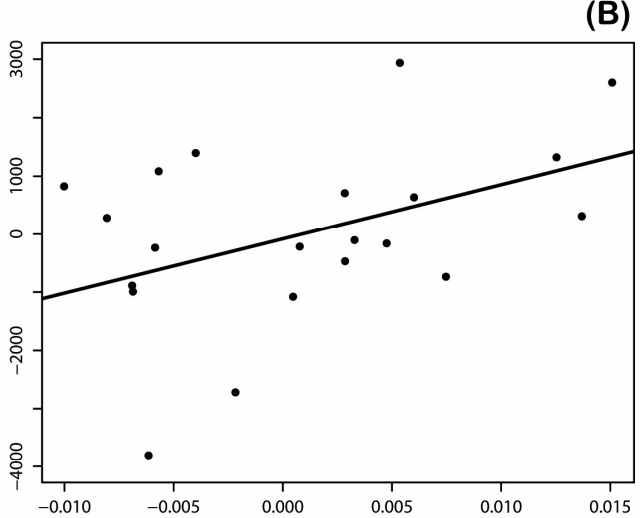

(D)

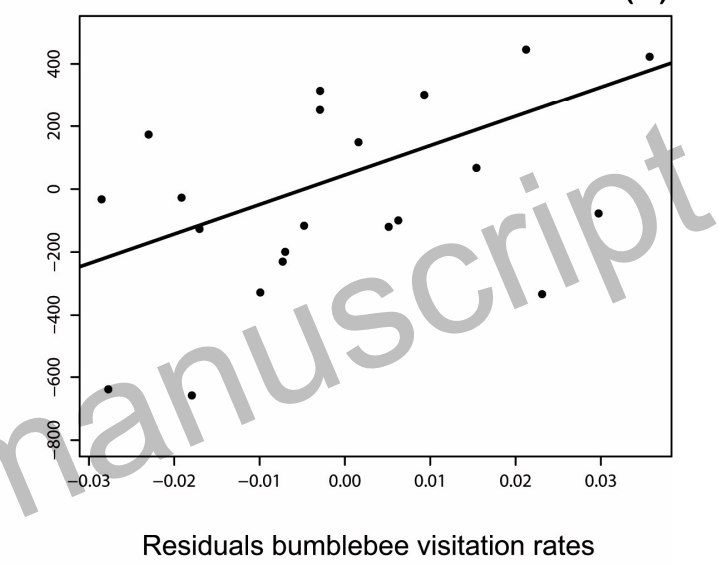


Fig.2.

(A)

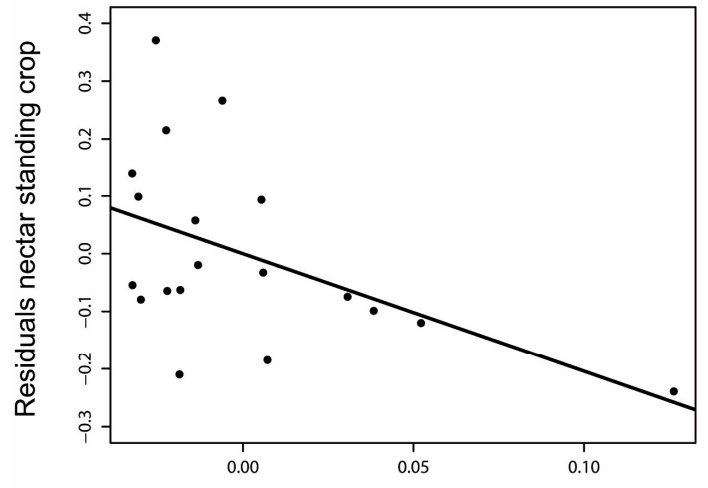

666
(B)

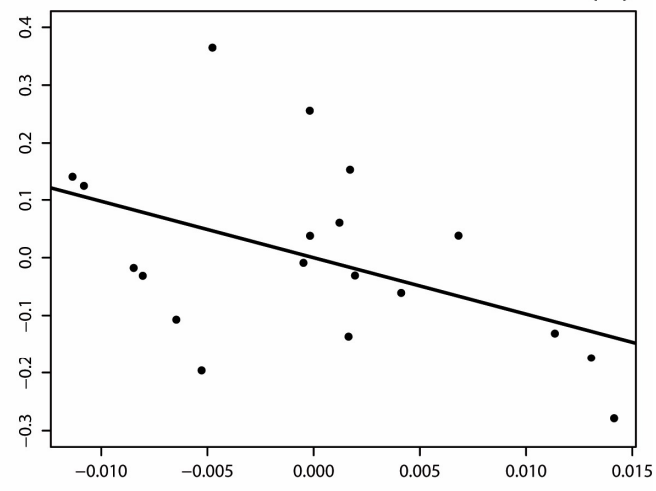

Residuals bumblebee visitation rates

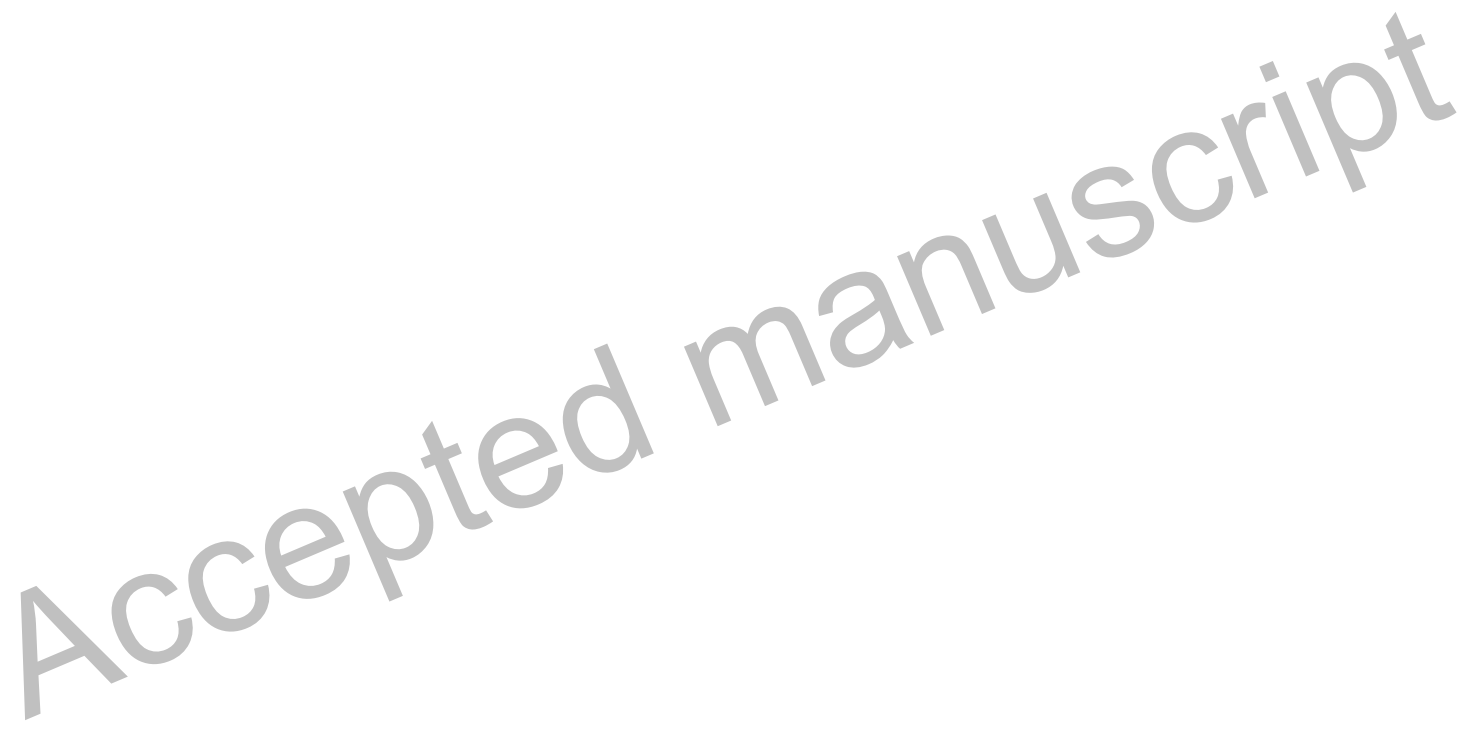


667

668

Fig.3

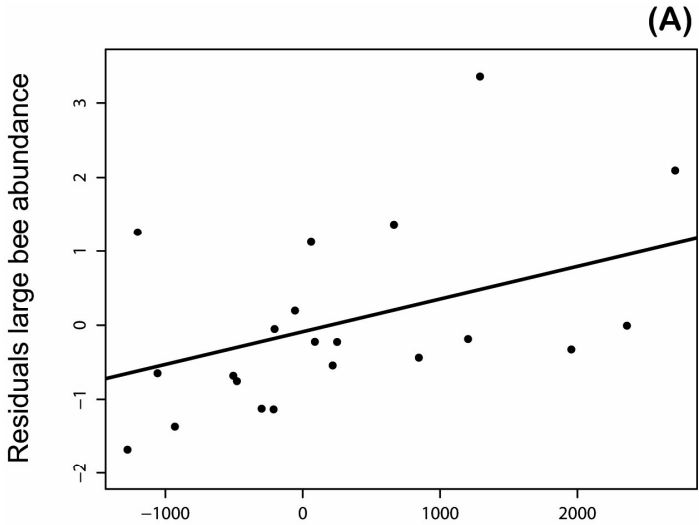

(A)

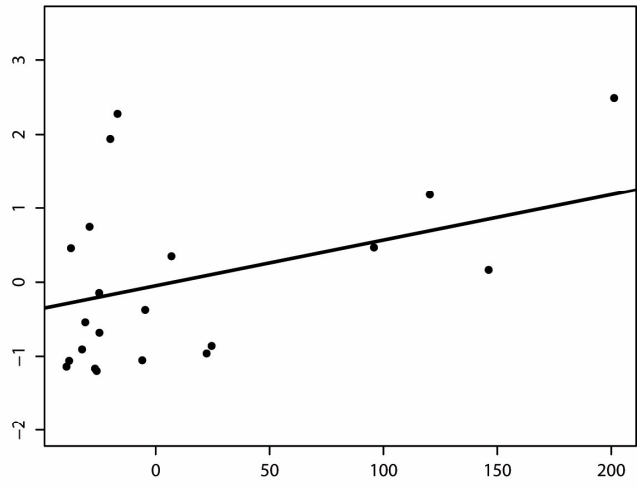

(C)

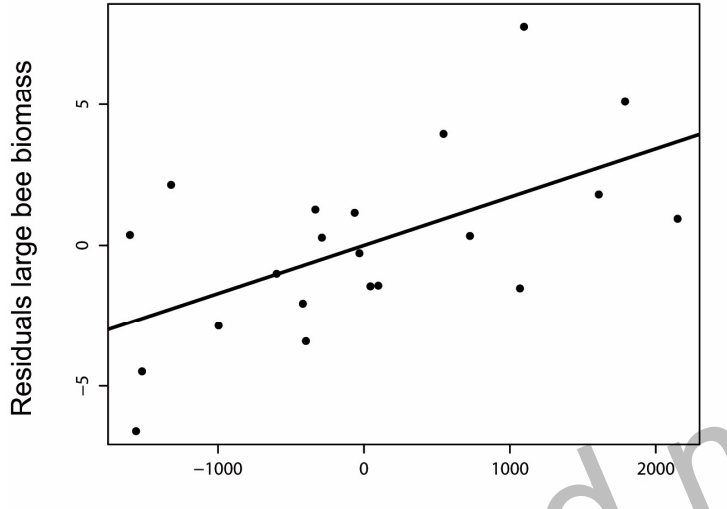

669

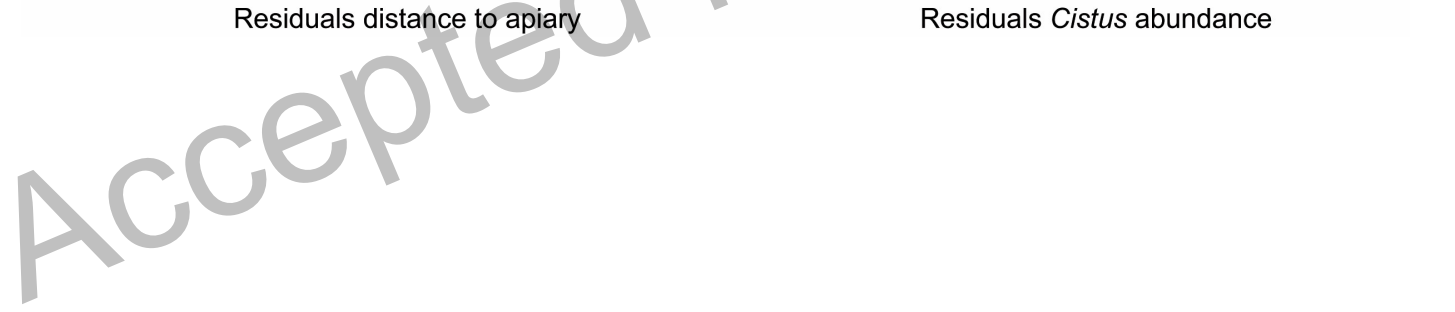

